\title{
AS FRONTEIRAS DO INTERIOR: O ALDEAMENTO INDÍGENA SÃO PEDRO DE ALCÂNTARA E SUAS INTERAÇÕES SOCIAIS NO ESPAÇO SERTANEJO - PARANÁ: 1876/1881
}

\author{
Maicon Fernando Marcante \\ Orientação: Carlos Alberto Medeiros Lima
}

PALAVRAS-CHAVE: fronteira agrária, aldeamentos indígenas, interações sociais.

Atento às reflexões referentes ao contato entre as sociedades tradicionais e a sociedade moderna hegemônica, a presente monografia apresenta como tema de análise as interações estabelecidas entre os grupos indígenas interioranos e os atores sociais posicionados à frente do processo de expansão da fronteira agrária na região do atual Paraná. Para Manuela Carneiro da Cunha ${ }^{1}$, a questão indígena no século XIX deixa de ser uma questão de mãode-obra, como foi durante o período colonial, e configura-se essencialmente numa questão de terras. As produções mais recentes ${ }^{2}$

${ }^{1}$ CUNHA, Manuela Carneiro da (org.). Legislação Indigenista no século XIX. EDUSP: São Paulo, 1992. A autora destaca, entretanto, algumas variações regionais: na região amazônica o trabalho indígena permaneceu fundamental; na região do Mato Grosso e do Paraná, a abertura e manutenção de rotas fluviais exigiram a submissão dos grupos indígenas.

2 AMOROSO, Marta Rosa. Catequese e Evasão. Etnografia do Aldeamento Indígena de São Pedro de Alcântara, Paraná (1855-1895). Tese de doutoramento/USP, São Paulo: 1998. MOTA, L. T. As colônias indígenas no Paraná Provincial. Aos Quatro Ventos, Curitiba: 2000. JEHA, S. C. O padre, o militar e o índio. Dissertação de mestrado/UFF, Niterói: 2005. TAKATUZI, T. Águas Batismais e Santos óleos: uma trajetória histórica do Aldeamento de Atalaia. Dissertação de Mestrado/UNICAMP, Campinas: 2005. FARAGE, N. As muralhas dos sertões: os povos indígenas no Rio Branco e a colonização. Paz e Terra/ANPOCS: 1991. ALEGRE, M. S. P. Aldeias indígenas e povoamento do Nordeste no final do século XVIII: aspectos demográficos da "cultura de contato". In: DINIZ, E.; LOPES, J.; PRANDI, J. (Org.) Ciências Sociais Hoje 1993. HUCITEC/ANPOCS, São Paulo: 1993. 
referentes aos aldeamentos indígenas, realizadas por historiadores e antropólogos, voltam-se às ações políticas e aos processos de ressignificação dos grupos indígenas na situação de aldeados, ou seja, enfatizam a posição dos mesmos como atores sociais no processo de contato com a sociedade moderna.

Tendo em vista estas perspectivas, o objetivo geral da presente monografia é apreender as interações sociais ocorridas nas fronteiras étnicas do aldeamento indígena São Pedro de Alcântara localizado no interior da província do Paraná - e, a partir de sua análise, apreender o próprio aldeamento em sua inserção no espaço sertanejo. Para tanto, utilizo os princípios de abordagem apresentados por Fredrik Barth ${ }^{3}$, nos quais os grupos étnicos são atribuições e identificações empregadas pelos seus próprios atores e, desta forma, organizam as relações entre seus componentes e os agentes externos. Ou seja, trata-se de observar a importância das interações étnicas - da constituição e manutenção de fronteiras étnicas - para a etnicidade dos grupos envolvidos. Ainda sobre as discussões apontadas, Maria Regina Celestino de Almeida ${ }^{4}$ comenta que os debates atuais nos campos da história e da antropologia nos conduzem "à quebra da dualidade entre o mundo dos brancos e o mundo dos índios". Nas suas palavras: "A idéia de processo para a compreensão das mudanças pelas quais passam os grupos indígenas em contato com as sociedades ocidentais (...) [enfatiza] as amplas possibilidades desses grupos para recriarem seus valores, tradições, culturas, histórias e identidades. Tal concepção é fundamental para se pensar as aldeias coloniais...".

Entre os objetivos específicos figura-se apreender aspectos dos atores sociais que conviviam e interagiam com o aldeamento; as formas e a dinâmica destas interações; a dinâmica da

\footnotetext{
${ }^{3}$ BARTH, Fredrik. O guru, o iniciador e outras variações antropológicas. Contra capa Livraria, Rio de Janeiro: 2000.

4 ALMEIDA, M. R. C. Metamorfoses Indígenas. Arquivo Nacional, Rio de Janeiro: 2003.

${ }^{5}$ Idem. Citações retiradas das páginas 259 e 260.
} 
comercialização de gêneros agrícolas produzidos pelos grupos aldeados; o engajamento dos indígenas nas atividades produtivas; e, por fim, os impactos do choque microbiano envolvendo os grupos indígenas aldeados, agregados e mesmo sertanejos. O recorte temporal justifica-se pelos acontecimentos da segunda metade da década de 1870 que desestabilizaram o aldeamento e proporcionaram relatos mais abundantes acerca do contato envolvendo os grupos aldeados e os atores sociais externos. O principal corpo documental utilizado é composto por ofícios do missionário e diretor do aldeamento - frei Timotheo de Castelnuovo - dirigidos à Província do Paraná ${ }^{6}$. Analisa-se também a lista de qualificação de votantes do município de Tibagi, de janeiro de $1877^{7}$, com vistas à apreensão de aspectos e características da sociedade tibagiana.

Inicialmente, apresenta-se um panorama geral do aldeamento: sua criação envolvendo o Barão de Antonina, a abertura da rota fluvial para o Mato Grosso e a migração dos Kaiowá envolvidos neste processo; a Guerra do Paraguai; características da legislação indigenista do período; por fim, a presença capuchinha nos aldeamentos indígenas.

Em seguida, a partir da análise da lista de votantes de Tibagi, apreendem-se aspectos e características da sociedade posicionada no entorno dos aldeamentos indígenas interligados ao rio Tibagi ${ }^{8}$. Os estudos com base em listas de qualificação de votantes permitem acessar informações sócio-profissionais referentes aos atores sociais qualificados ${ }^{9}$. Neste sentido, a análise aqui apresentada objetivou

\footnotetext{
${ }^{6}$ Disponíveis no Arquivo Público do Paraná [DEAPP].

${ }^{7}$ Disponível no Arquivo Público do Paraná [DEAPP].

${ }^{8}$ Entre 1855 e 1920, a bacia do rio Paraná abrigou 06 projetos de aldeamentos indígenas. As experiências mais duradouras foram os aldeamentos São Pedro de Alcântara (1855-1895) e São Jerônimo (1859-1920). Sobre o assunto ver MOTA, L. As colônias indigenas..., pp. 42 e seguintes.

${ }^{9}$ Sobre o assunto ver LINHARES \& SILVA. Uma fonte demográfica para a história Social do Brasil (1850-1890): as listas eleitorais. In.: Anais do III Encontro Nacional de Estudos Populacionais. Belo Horizonte: ABEP, 1982. Segundo os autores, para o período do Brasil Imperial, as listas eleitorais - listas de
} 
caracterizar a sociedade envolvida na comercialização da produção agrícola de São Pedro de Alcântara.

Verificamos, grosso modo, a presença de uma elite mercantil posicionada sobre a maior parte da população composta por produtores rurais pobres. Tratando as informações separadas pelos quarteirões do município, verificamos na área central de Tibagi a presença expressiva de negociantes com rendimentos modestos, ou seja, pequenos comerciantes. Observamos ainda a existência de localidades de caráter eminentemente agrário e outras com um número relativamente expressivo de negociantes. Sobre a freguesia do Jataí, região que compreendia os aldeamentos São Pedro de Alcântara e São Jerônimo, verificou-se que a mesma não figurava como uma área comercial de relativa expressão, sendo possível e mesmo provável que a comercialização dos produtos da freguesia inclusive dos aldeamentos - fosse realizada por negociantes de outras áreas do município. Concluímos, neste capítulo, que as elites mercantis locais - e mesmo os pequenos negociantes - não nutriam, necessariamente, interesses contrários à manutenção dos aldeamentos indígenas próximos ao rio Tibagi. Verificamos, portanto, que as interações envolvendo a sociedade tibagiana e os grupos indígenas aldeados não se resumiam à luta pela expropriação dos territórios dos aldeamentos, mostrando-se particularmente mais complexas.

Em seguida, a partir dos ofícios de Castelnuovo, abordam-se a dinâmica e a forma das relações comerciais envolvendo as produções dos grupos aldeados. Durante a década de 1870, tanto os indígenas aldeados como os "moradores" do aldeamento produziam gêneros agrícolas e aguardente para comercialização ${ }^{10}$. Em 1879, frei

qualificação de votantes - são fontes com informações sócio-profissionais precisas e passíveis de seriação.

${ }^{10} \mathrm{O}$ presidente Lamenha Lins relata, em 1877, que os Kaingang de São Pedro de Alcântara produziram 288 mil litros de milho, entre outros produtos. Já os Kaiowá apresentaram uma produção mais modesta: cerca de 70 mil litros de milho, além de feijão, açúcar e arroz em menor escala. Com estas produções os Kaiowá obtiveram um rendimento de mais de quatro contos de réis e os Kaingang quase seis contos 
Castelnuovo, respondendo críticas realizadas pela Câmara de Tibagi relativas à cobrança de impostos, defende-se das acusações fornecendo informações fundamentais sobre a comercialização da produção do aldeamento. A partir da análise destas informações, verificamos que Castelnuovo intermediava a comercialização de parte da produção dos indígenas aldeados - que podemos especular significativa devido à atenção dada pela Câmara a esta intermediação. Por outro lado, o missionário revela que negociantes, destacadamente os negociantes de Tibagi, também procuravam diretamente os indígenas aldeados para comprar sua produção.

$\mathrm{O}$ envolvimento dos grupos aldeados nas atividades produtivas vinculadas ao aldeamento também foi considerado ${ }^{11}$. Verificou-se, a partir dos ofícios de Castelnuovo, que as diferentes etnias desenvolveram formas distintas de engajamento nas atividades produtivas frente ao aldeamento e à sociedade tibagiana. Os Kaingang, por um lado, envolveram-se de forma mais intensa na produção agrícola vinculada ao aldeamento e voltada à comercialização. Os Kaiowá, por outro lado, converteram-se, de forma geral, em jornaleiros que trabalhavam em grupo - às vezes composto por quatro ou cinco pessoas, às vezes por mais de vinte indígenas - para produtores rurais das proximidades de São Pedro de Alcântara e da colônia militar do Jataí, bem como para a administração do próprio aldeamento e na abertura e manutenção das estradas da região.

Por fim, também a partir dos ofícios de Castelnuovo, foram analisados aspectos do desenvolvimento, no início de 1877 , de uma

de réis. Relatório citado disponível no site do DEAPP: http://www.pr.gov.br/arquivopublico/relatorio_pres.shtml.

11 De acordo com Marta Amoroso, tanto os Kaiowá como os Kaingang foram gradativamente se envolvendo nos negócios do aldeamento que já em fins da década de 1860 ingressara definitivamente na economia de mercado. AMOROSO, M. Catequese e Evasão..., p. 174. 
epidemia de varíola em São Pedro de Alcântara ${ }^{12}$. Nos ofícios analisados, Castelnuovo destaca que um morador do Jataí regressou da vila de Tibagi contaminado pela doença. $\mathrm{Na}$ descrição do missionário, portanto, a varíola chegou ao aldeamento e à colônia do Jataí através do contato com a vila de Tibagi. Em meados de 1877, Castelnuovo relata que a epidemia assolou também os sertões próximos ao rio Paraná e seus afluentes e disseminou-se tanto entre os indios Guarani e Caiguas como também entre o nosso povo ${ }^{13}$. Concluímos neste capítulo que a epidemia de varíola que atingiu São Pedro de Alcântara no ano de 1877 seguiu uma trajetória partindo da vila de Tibagi, disseminando-se em seguida pelas áreas próximas à bacia do rio Paraná. O aldeamento desempenhou papel fundamental neste processo, visto que os Kaiowá aldeados foram contaminados e ou morreram ou partiram infectados Tibagi abaixo.

De forma geral, conclui-se na presente monografia que as relações sociais envolvendo os grupos indígenas aldeados em São Pedro de Alcântara, pertencentes às etnias Kaingang e Kaiowá, e a sociedade de seu entorno - ou mesmo as interações étnicas que tinham lugar no interior do aldeamento - apresentavam uma dinâmica bastante complexa. A diversidade das situações verificadas - engajamentos, resistências, alianças, conflitos, apropriações, choques microbianos - bem como as segmentações inerentes aos atores sociais envolvidos - aos grupos indígenas e mesmo às frentes de expansão da fronteira agrária - configuraram um cenário híbrido e complexo que interferiu decisivamente no processo de incorporação política dos grupos indígenas da região do atual Paraná. Neste sentido, as perspectivas que consideram apenas o contexto institucional ou legal relacionado à criação dos aldeamentos, os interesses ligados às aberturas de rotas para o Mato Grosso, a

\footnotetext{
12 Sobre as epidemias nos aldeamentos do rio Tibagi ver AMOROSO, M. Catequese e evasão..., pp. 199-200; e MOTA, L. As colônias indígenas..., pp. 8891.

13 Castelnuovo utilizava a expressão nosso povo para designar os moradores cristãos do aldeamento e/ou das regiões próximas.
} 
imposição cristã da catequese e de seus princípios, a unidade dos interesses tanto de indígenas como das elites locais, a completa submissão dos grupos indígenas, mostram-se particularmente limitadas frente à complexidade das relações e interações sociais verificadas na presente monografia. 